\title{
Changes in mandibular movement during chewing of different hardness foods
}

\author{
Marie Komino $^{1} \cdot$ Hiroshi Shiga ${ }^{1}$
}

Received: 4 October 2016/ Accepted: 20 December 2016/Published online: 1 February 2017

(C) The Author(s) 2017. This article is published with open access at Springerlink.com

\begin{abstract}
In order to clarify the change in mandibular movement during chewing of foods with different hardness, 20 healthy subjects were asked to chew 3 types of gummy jellies (containing 6, 8, and 10\% gelatin), and the masseter muscular activity and the mandibular movement were recorded. The indicators representing the muscular activity (integral value of masseter muscular activity), the mandibular movement (opening distance, masticatory width, cycle time, opening maximum velocity and closing maximum velocity), and the stability of masticatory movement were calculated, respectively, and compared among the three foods. The integral value of masseter muscular activity was smallest for the $6 \%$ gelatin and significantly increased in order as the content of gelatin increased to $8,10 \%$. The value of each indicator for the mandibular movement increased gradually as the food got harder. The value for all indicators was significantly larger for the 10 than the $6 \%$. However, between the two foods, no significant change was observed for the several indicators. The mean ratio of the $10 \%$ gelatin to the $8 \%$ gelatin for the cycle time was extremely small, being 1.01 , but was between the range of 0.89-1.07 showing aspects of changes within each individual. The other indicators showing small ratio were similar in this aspect. The parameters representing stability of movement showed the lowest values for the $8 \%$ gelatin. It was suggested that the hardness of food affected mandibular movement during mastication, but the
\end{abstract}

Hiroshi Shiga

h-shiga@tky.ndu.ac.jp

1 Department of Partial and Complete Denture, The Nippon Dental University School of Life Dentistry, 1-9-20 Fujimi, Chiyoda-Ku, Tokyo 102-8159, Japan movement changed variously according to the hardness and exerted muscular activities.

Keywords Masticatory movement $\cdot$ Masseter muscular activity $\cdot$ Food hardness - Gummy jelly

\section{Introduction}

Although mastication is maintained in a rhythmic pattern by the central pattern generator located in the brainstem [1], it is also autoregulated by feedback signals from peripheral sensory receptors [2-4].

It has been reported that masticatory movements are influenced by foods and vary with the type of foods, particularly with varying food textures, and many studies have been carried out to explore the effects of differences in the size and hardness of foods on the masticatory movement [5-18].

Based on the results of studies conducted to determine the effect of the size on the masticatory movement, there is unanimity of the opinion that the cycle time tends to be prolonged with increasing size of food, and the masticatory muscular activity, amount of movement, and also the velocity of movement increase $[8,9,12,13]$. With respect to the hardness of food, there is consensus of opinion that the masticatory muscular activity increases with increasing hardness of food, although there is still lack of unanimity with respect to the influence on the cycle time, amount of movement, and velocity of movement [5-7, 10, 11, 14-18].

When viewed from the angle of test food, different types of foods were used in some of the studies carried out to determine the changes in the masticatory movement associated with different levels of hardness of foods [5-7, 16], whereas test food of the same type was used in studies 
conducted to determine the differences in the masticatory movements associated with different sizes [8, 9, 12, 13]. While carrying out experiments using different types of foods, which would differ in size and weight of the food, the influence of differences in the latter may have an influence on the results. Therefore, it may be desirable to carry out evaluations using a test food whose degree of hardness alone can be modified whenever necessary, and eliminate the effects of size and weight.

In this study, in order to clarify the change in mandibular movement during chewing of foods with different hardness, we analyzed the opening distance, masticatory width, cycle time, maximum velocity, and masseter muscular activity in healthy subjects while they chewed foods of varying degrees of hardness; the food was gummy jelly with same size and weight, but varying in hardness.

\section{Materials and methods}

\section{Ethics statement}

All the experimental procedures were approved by the Ethics Committee of Nippon Dental University (NDUT2012-29, T2013-2015). Informed consent was obtained from all the subjects after they were received the general nature of the study.

\section{Subjects}

Twenty healthy subjects (10 males and 10 females, 20-39 years of age, average; 26.8 years) participated in this study. None of the subjects had any clinical abnormalities in the masticatory system. The following selection criteria were applied: no complaints about bite; possession of a full complement of teeth excluding the third molars; no major dental restorations, and no history of orthodontic treatment. All the subjects were able to distinguish their habitual chewing side which was one of the requirements.

\section{Test food}

Three types of gummy jellies having different hardness, containing 6,8 , and $10 \%$ gelatin were prepared, based on gummy jelly containing $8 \%$ gelatin which has been confirmed as being able to be masticated unconsciously [19, 20].

The test food was cylindrical in shape with a diameter of $14 \mathrm{~mm}$, height of $8 \mathrm{~mm}$, and weight of $2 \mathrm{~g}$ (Table 1).

\section{Hardness of test food}

The hardness of food was measured at approximately $25{ }^{\circ} \mathrm{C}$ using a texture analyser (TA.XT PLUS, EKO,
Table 1 The size, weight, hardness, and ingredients of the gummy jelly

\begin{tabular}{llll}
\hline Size $(\mathrm{mm})$ & & $\phi 14 \times 8$ & \\
Weight $(\mathrm{g})$ & & 2 & \\
Hardness $(\mathrm{kPa})$ & 69.8 & 109.6 & 150.2 \\
Ingredient $(\% \mathrm{w} / \mathrm{w})$ & & & \\
$\quad$ Gelatin & 6 & 40 & 10 \\
Maltose & 40 & 10 & 40 \\
Solbitol & 10 & 5 & 10 \\
Glucose & 5 & 37 & 5 \\
Others (water) & 39 & & 35 \\
\hline
\end{tabular}

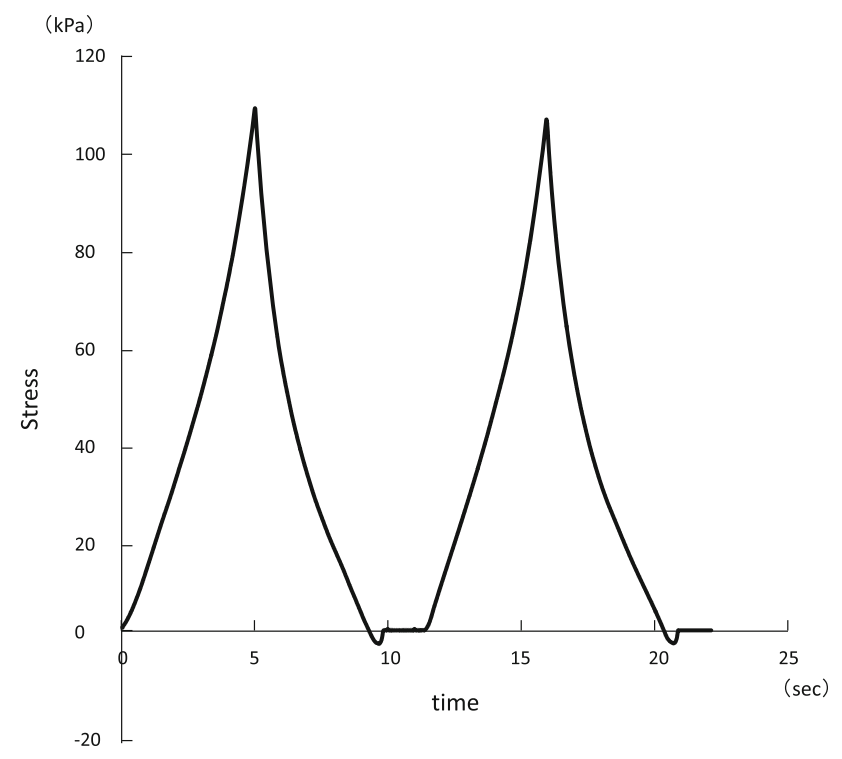

Fig. 1 Texture profile curve for the test food. Hardness is defined as the maximum stress value of the first compression curve, (example of the gummy jelly containing $8 \%$ gelatin)

Tokyo, Japan). Compressions were performed at a constant displacement rate of $1.0 \mathrm{~mm} / \mathrm{s}$ and at a compression ratio of $50 \%$ of the original sample height. Five samples for each hardness were tested and the resulting values averaged (Table 1; Fig. 1).

\section{Recording method}

The subjects were asked to chew 3 types of gummy jellies on their habitual chewing side for $20 \mathrm{~s}$. The order of the three types of food in each chewing was done randomly and 5 min interval between each mastication was set. The masseter muscular activity was recorded by surface electromyography (RM6000, Nihon Koden, Tokyo, JAPAN) for both left and right masseter muscles. The movement of the mandibular incisal point was recorded by a mandibular kinesiograph (MKG K6I, Myotronics, Seattle, WA, USA). The muscular activity and the mandibular movement were 
collected simultaneously using a data recorder (XR-5000, TEAC, Tokyo, JAPAN). Indicators representing the masseter muscular activity and movement of the mandibular incisal point were established as below.

\section{Masseter muscular activity}

For the masseter muscular activity, the analog signals from the data recorder were converted into digital signals at $2,000 \mathrm{~Hz}$. For the ten cycles from the fifth cycle of mastication, the integral value of muscular activities of each cycle on the habitual chewing side was calculated by establishing on the display, using a mouse, the beginning and the ending of electrical discharge of each masticatory cycle's muscular activities (Fig. 2). Then the mean value of ten cycles was used as the indicator.

From the research [21] that we have done in the past, the results of investigating the amount of movement, cycle time, and muscular activities on the first 10 cycles of masticating various types of food showed that the changes were large for the first few cycles of mastication and thereafter the changes became smaller. Also, it has been

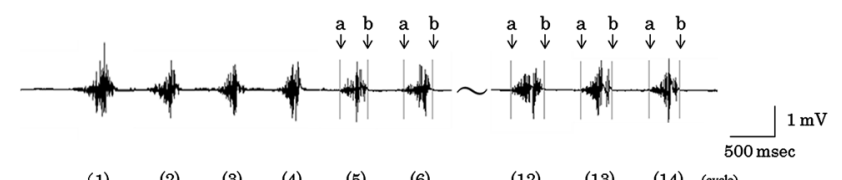

Fig. 2 Masseter electromyograph of the 1st-6th and the 12th-14th cycles. a beginning of electrical discharge, $\mathbf{b}$ ending of electrical discharge, (example of the subject 1) confirmed that in order to evaluate the stability of the movement it is most suitable to use the 10 cycles from the fifth cycle of mastication [9, 22]. Then, in this study the 10 cycles from the 5 th cycle were chosen.

\section{Movement of the mandibular incisal point}

For the mandibular incisal point, the analog signals from the data recorder were converted into digital signals at $100 \mathrm{~Hz}$ and the indicators representing the path, rhythm, and velocity of masticatory movement, and stability of masticatory movement path and rhythm for ten cycles from the fifth cycle were calculated. The indicators were calculated as follows.

- Masticatory movement path and stability of masticatory movement path

The average path was calculated from the opening and closing paths, consisting of vertical and lateral components, of mandibular movement in the 10 cycles from the 5th cycle [9, 23] (Fig. 3). The opening distance and masticatory width were used as indicators representing the masticatory movement path. The opening distance was defined as the vertical distance from the maximum intercuspal position (MIP, level 0) to the maximum jaw opening (level 10), and the masticatory width was defined as the average width from the first to the ninth level. The average of the 11 standard deviations (SDs) from level 0 to the 10th level in the horizontal direction during opening movement, in the horizontal direction during the closing movement, and in the vertical direction were calculated as the opening lateral component, closing lateral component and vertical
Fig. 3 Method used to calculate the average path. a Ten cycles consisting of the vertical component and lateral component, b Ten cycles consisting of the vertical component and velocity component, c Overlapping of each cycle of $A$ and average path and SDs of each level, d Overlapping of each cycle of $B$ and average path and SDs of each level. MIP maximum intercuspal position, level 0 : MIP, level 10: maximum jaw opening,-—: masticatory width, (example of the subject 1)

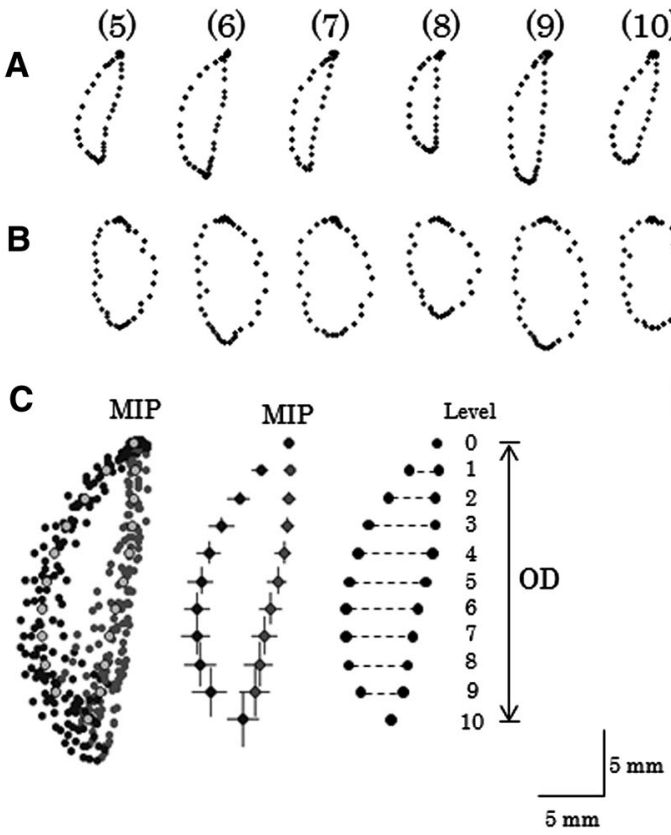

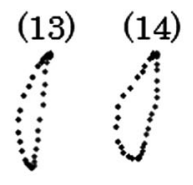

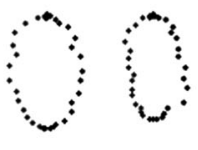

D

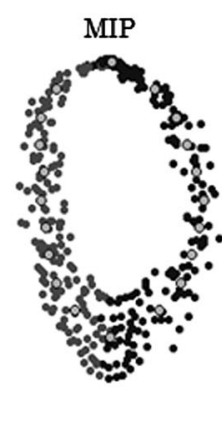

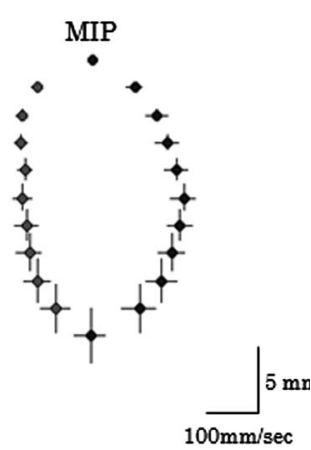


Table 2 Numerical data of the average path and velocity component

\begin{tabular}{|c|c|c|c|c|c|c|c|c|c|c|c|}
\hline \multirow[t]{3}{*}{ Level } & \multicolumn{4}{|c|}{ Lateral component (mm) } & \multirow[t]{3}{*}{ Width (mm) } & \multirow{2}{*}{\multicolumn{2}{|c|}{ Vertical component (mm) }} & \multicolumn{4}{|c|}{ Velocity component $(\mathrm{mm} / \mathrm{sec})$} \\
\hline & \multicolumn{2}{|c|}{ Opening } & \multicolumn{2}{|c|}{ Closing } & & & & \multicolumn{2}{|c|}{ Opening } & \multicolumn{2}{|c|}{ Closing } \\
\hline & Mean & SD & Mean & SD & & Mean & SD & Mean & SD & Mean & SD \\
\hline 0 & 0.0 & 0.1 & 0.0 & 0.1 & & 0.0 & 0.1 & 0.0 & 6.0 & 0.0 & 6.0 \\
\hline 1 & -0.1 & 0.4 & 2.0 & 0.6 & 2.1 & 1.9 & 0.2 & 124.3 & 13.1 & 94.8 & 23.0 \\
\hline 2 & -0.1 & 0.4 & 3.6 & 0.8 & 3.7 & 3.9 & 0.4 & 158.3 & 15.8 & 145.2 & 23.9 \\
\hline 3 & 0.0 & 0.5 & 4.9 & 0.9 & 4.9 & 5.9 & 0.6 & $160.7^{\mathrm{f}}$ & 14.6 & 167.9 & 24.9 \\
\hline 4 & 0.3 & 0.5 & 5.9 & 0.9 & 5.6 & 7.9 & 0.8 & 152.0 & 18.5 & 190.3 & 24.5 \\
\hline 5 & 0.8 & 0.7 & 6.5 & 0.9 & 5.7 & 9.9 & 0.9 & 156.3 & 26.3 & $204.7^{\mathrm{g}}$ & 18.7 \\
\hline 6 & 1.3 & 0.8 & 6.8 & 0.9 & 5.5 & 11.9 & 1.1 & 147.3 & 21.9 & 196.9 & 19.4 \\
\hline 7 & 1.7 & 0.9 & 6.8 & 1.0 & 5.1 & 13.9 & 1.3 & 141.3 & 14.8 & 179.1 & 7.1 \\
\hline 8 & 2.2 & 1.0 & 6.6 & 1.2 & 4.4 & 15.8 & 1.5 & 124.0 & 15.6 & 155.8 & 18.4 \\
\hline 9 & 2.5 & 1.1 & 5.8 & 1.3 & 3.3 & 17.8 & 1.7 & 82.9 & 18.6 & 105.0 & 20.8 \\
\hline 10 & 3.4 & 1.2 & 3.4 & 1.2 & & $19.8^{\mathrm{a}}$ & 1.9 & 4.7 & 9.3 & 4.7 & 9.3 \\
\hline \multicolumn{2}{|l|}{ Mean } & 0.73 & & 0.93 & $4.5^{\mathrm{b}}$ & & 1.00 & 138.6 & & 160.0 & \\
\hline \multicolumn{2}{|c|}{ SD/OD (\%) } & $3.69^{c}$ & & $4.70^{\mathrm{d}}$ & & & $5.05^{\mathrm{e}}$ & & & & \\
\hline
\end{tabular}

a Opening distance (OD)

${ }^{\mathrm{b}}$ Masticatory width

c Standard deviation/opening distance (SD/OD) of opening lateral component

${ }^{d} \mathrm{SD} / \mathrm{OD}$ of closing lateral component

${ }^{\text {e }} \mathrm{SD} / \mathrm{OD}$ of vertical component

${ }^{\mathrm{f}}$ Opening maximum velocity

g Closing maximum velocity

component, respectively. Then, these values were divided by the opening distance, and the resulting values (standard deviation/opening distance, SD/OD) were used as the three indicators representing the stability of the masticatory path (Table 2).

- Masticatory movement rhythm and stability of masticatory movement rhythm

For 10 cycles from the fifth cycle the cycle time was calculated. And then the coefficient of variation (CV) was obtained from the mean time of the ten cycles and its standard deviation, and the mean value was used as masticatory movement rhythm, and the CV was used to represent the stability of masticatory movement rhythm.

\section{Masticatory movement velocity}

From the opening and closing paths consisting of vertical component and velocity component, the average path was calculated as well as masticatory movement path (Fig. 2). The maximum values of opening and closing movement on the average path were used as opening maximum velocity and closing maximum velocity (Table 2).

\section{Statistical analysis}

The indicators representing the masseter muscular activity and the mandibular movement were compared among the 3 types of foods with different hardness. All the data were analyzed with statistical software (SPSS for Windows 10.0 J, SPSS, Chicago, IL, USA). The significance of differences among the 3 types of foods was evaluated by analysis of variance (ANOVA). When significant effects were identified, Bonferroni's multiple comparison test was performed. All statistical analyses were performed with significance set at the 0.05 and 0.01 probability levels.

\section{Results}

The integral value of masseter muscular activity was smallest for the $6 \%$ gelatin and increased in order as the content of gelatin increased to $8,10 \%$. A significant difference was found between all three foods (Table 3).

The value of each indicator for the masticatory movement path, the masticatory movement rhythm, and the masticatory movement velocity increased gradually as the 
Table $3 F$ ratio (ANOVA), mean values and their standard deviations for the values of the masticatory movement path, masticatory movement rhythm, masticatory movement velocity, and muscular activity with differing gelatin concentrations

\begin{tabular}{|c|c|c|c|c|c|c|c|}
\hline & \multirow[t]{2}{*}{$F$ ratio } & \multirow[t]{2}{*}{$6 \%$} & \multirow[t]{2}{*}{$8 \%$} & \multirow[t]{2}{*}{$10 \%$} & \multicolumn{3}{|c|}{$P$ value } \\
\hline & & & & & $6-8 \%$ & $6-10 \%$ & $8-10 \%$ \\
\hline \multicolumn{8}{|l|}{ Masticatory movement path } \\
\hline Opening distance $(\mathrm{mm})$ & $67 * *$ & $15.6 \pm 1.6$ & $18.1 \pm 2.3$ & $18.4 \pm 2.3$ & 0.000 & 0.000 & 0.729 \\
\hline Masticatory width (mm) & $34 * *$ & $2.7 \pm 0.6$ & $2.8 \pm 0.6$ & $3.4 \pm 0.8$ & 0.705 & 0.000 & 0.000 \\
\hline \multicolumn{8}{|l|}{ Masticatory movement rhythm } \\
\hline Cycle time (msec) & $7 *$ & $603.5 \pm 61.9$ & $620.2 \pm 73.3$ & $622.7 \pm 56.6$ & 0.059 & 0.002 & 0.646 \\
\hline \multicolumn{8}{|l|}{ Masticatory movement velocity } \\
\hline Opening maximum velocity $(\mathrm{mm} / \mathrm{sec})$ & $25 * *$ & $142.5 \pm 29.8$ & $159.7 \pm 33.5$ & $168.5 \pm 35.5$ & 0.000 & 0.000 & 0.072 \\
\hline Closing maximum velocity $(\mathrm{mm} / \mathrm{sec})$ & $28 * *$ & $127.9 \pm 24.6$ & $143.3 \pm 26.3$ & $151.7 \pm 25.6$ & 0.000 & 0.000 & 0.053 \\
\hline \multicolumn{8}{|l|}{ Muscular activity } \\
\hline Integral value of masseter muscular activity ( $\mathrm{mV} \mathrm{msec}$ ) & $70 * *$ & $28.2 \pm 11.3$ & $33.2 \pm 14.4$ & $39.0 \pm 15.6$ & 0.000 & 0.000 & 0.000 \\
\hline
\end{tabular}

$* P<0.05, * * P<0.01$

food got harder. The value for all indicators was significantly larger for chewing food containing $10 \%$ gelatin than chewing food containing $6 \%$ gelatin (Table 3). However, between the food containing $6 \%$ gelatin and the food containing $8 \%$ gelatin, significant change was observed for the opening distance and the maximum velocity of opening and closing, but no significant change was observed for the masticatory width and the cycle time. Between food containing $8 \%$ gelatin and food containing $10 \%$ gelatin, significant change was observed for the masticatory width, but no significant change was observed for the other indicators (Table 3).

The mean ratio of the $6 \%$ gelatin to the $8 \%$ gelatin was $0.87,0.90,0.90$ for the opening distance, the opening maximum velocity, and the closing maximum velocity, respectively, but was small for the masticatory width and the cycle time being 0.96 and 0.98 , respectively. The mean ratio of the $10 \%$ gelatin to the $8 \%$ gelatin was 1.21 for the masticatory width, but was small for the opening distance, the cycle time, the opening maximum velocity, and the closing maximum velocity being $1.02,1.01,1.06,1.07$. The mean ratio of the $10 \%$ gelatin to the $8 \%$ gelatin was extremely small being 1.01 , but was between the range of 0.89-1.07 showing aspects of changes within each individual. The other indicators showing small ratio were similar in this aspect (Table 4).

The parameters representing stability of movement showed the lowest values for the $8 \%$ gelatin and increased in the order of the gelatin content of $6 \%$ and $10 \%$ (Table 5). All the parameters representing stability of movement showed the lowest values for the food with a gelatin content of $8 \%$, with the values tending to increase in the order of the gelatin content of the food of $6 \%$ and $10 \%$. Significant differences in these parameters were found between the $8 \%$ and the $10 \%$ in all the parameters, between the $6 \%$ and the $8 \%$ in the opening lateral component, and between the $6 \%$ and the $10 \%$ in the vertical component and the cycle time (Table 5).

\section{Discussion}

It has been reported that the muscular activity increases progressively with increasing hardness of foods [11, 14-18]. The result of this study also showed that the masseter muscular activity increased progressively with increasing hardness of the food, with significant differences between each pair of foods examined, consistent with previous reports [11, 14-18]. This may be interpreted as indicating that the chewing force increases in strength with increasing hardness of a food.

Many reports have demonstrated that the amount of masticatory movement increases with increasing hardness of the food $[6,7,10,11,15-18]$. In this study, the amount of movement was found to be the smallest for the food with the least gelatin content of $6 \%$ and progressively increased with increasing the food gelatin content (8 and 10\%). However, for the opening distance between the 8 and the $10 \%$, and for the masticatory width between the 6 and the $8 \%$, no significant differences were found between the two. This indicated that according to the hardness of food, there were differences in changes in the amount of vertical and lateral masticatory movements. It is easy to see the differences by the ratio. The ratio of the $6 \%$ to the $8 \%$ for the opening distance was 0.87 and a bit smaller than the ratio (0.96) for the masticatory width. On the other hand, the ratio of the $10 \%$ to the $8 \%$ for the masticatory width was 1.21 and a bit larger than the ratio (1.02) for the opening distance. On the other hand, the ratio of 10 to $8 \%$ was 1.02 for the opening distance and a bit larger, 1.21 for the 
Table 4 Ratio of the $6 \%$ to the $8 \%$ or the $10 \%$ to the $8 \%$ and the number of the ratio which are more or less than 1

\begin{tabular}{|c|c|c|c|c|c|c|c|c|c|c|}
\hline & \multicolumn{4}{|c|}{ Masticatory movement path } & \multirow{2}{*}{\multicolumn{2}{|c|}{$\begin{array}{l}\text { Masticatory movement } \\
\text { rhythm }\end{array}$}} & \multicolumn{4}{|c|}{ Masticatory movement velocity } \\
\hline & \multicolumn{2}{|c|}{ Opening distance } & \multicolumn{2}{|c|}{ Masticatory width } & & & \multicolumn{2}{|c|}{$\begin{array}{l}\text { Opening maximum } \\
\text { velocity }\end{array}$} & \multicolumn{2}{|c|}{$\begin{array}{l}\text { Closing maximum } \\
\text { velocity }\end{array}$} \\
\hline & $6 \% / 8 \%$ & $10 \% / 8 \%$ & $6 \% / 8 \%$ & $10 \% / 8 \%$ & $6 \% / 8 \%$ & $10 \% / 8 \%$ & $6 \% / 8 \%$ & $10 \% / 8 \%$ & $6 \% / 8 \%$ & $10 \% / 8 \%$ \\
\hline Mean & 0.87 & 1.02 & 0.96 & 1.21 & 0.98 & 1.01 & 0.90 & 1.06 & 0.90 & 1.07 \\
\hline Range & $074-0.96$ & $0.95-1.10$ & $0.81-1.14$ & $0.85-1.46$ & $0.90-1.07$ & $0.89-1.07$ & $0.74-1.06$ & $0.85-1.32$ & $0.68-1.10$ & $0.90-1.27$ \\
\hline$>1$ & 0 & 11 & 8 & 19 & 9 & 11 & 3 & 16 & 3 & 15 \\
\hline$<1$ & 20 & 9 & 12 & 1 & 11 & 9 & 17 & 4 & 17 & 5 \\
\hline
\end{tabular}

Table $5 F$ ratio (ANOVA), mean values and their standard deviations for the values of the stability of masticatory movement path and the stability of masticatory movement rhythm

\begin{tabular}{|c|c|c|c|c|c|c|c|}
\hline & \multirow[t]{2}{*}{$F$ ratio } & \multirow[t]{2}{*}{$6 \%$} & \multirow[t]{2}{*}{$8 \%$} & \multirow[t]{2}{*}{$10 \%$} & \multicolumn{3}{|l|}{$P$ value } \\
\hline & & & & & $6 \%-8 \%$ & $6 \%-10 \%$ & $8 \%-10 \%$ \\
\hline \multicolumn{8}{|c|}{ Stability of masticatory path } \\
\hline Opening lateral $(\%)$ & $9 * *$ & $4.3 \pm 1.6$ & $3.4 \pm 1.9$ & $4.9 \pm 1.5$ & 0.012 & 0.191 & 0.000 \\
\hline Closing lateral $(\%)$ & $4^{*}$ & $4.5 \pm 1.9$ & $3.7 \pm 1.4$ & $5.1 \pm 1.6$ & 0.172 & 0.121 & 0.001 \\
\hline Vertical (\%) & $9 * *$ & $5.1 \pm 1.4$ & $4.6 \pm 1.6$ & $6.3 \pm 2.1$ & 0.146 & 0.002 & 0.000 \\
\hline \multicolumn{8}{|c|}{ Stability of masticatory movement rhythm } \\
\hline Cycle time $(\%)$ & $13 * *$ & $5.3 \pm 1.9$ & $4.6 \pm 1.7$ & $6.4 \pm 2.4$ & 0.133 & 0.005 & 0.000 \\
\hline
\end{tabular}

masticatory width. This could be thought that the vertical masticatory movement increased when the hardness of food was relatively soft, and the lateral masticatory movement increased when the food got harder.

Kitashima et al. [24] investigated mandibular movements during the process of mastication of hard gummy jelly in terms of the movement stages, that is, the initial, middle, and final stages, and reported that both the opening distance and the masticatory width were the greatest in the initial stage, decreasing in the middle to the final stage. They also reported that while there was no significant difference in the opening distance between the initial and middle stages of mastication, the masticatory width differed significantly between these two stages. These results indicate that it is the amount of lateral movement rather than that of vertical movement which increases during mastication of hard foods. In this study, we obtained similar results from a comparison of gummy jelly with gelatin contents of 8 and $10 \%$.

Unlike other researchers, Pröschel et al. [5]. reported that the opening distance decreased whereas the masticatory width increased during mastication of hard foods. However, this may be explained as follows: because Pröschel et al. [5] used very hard wine gums as their hard food, the subjects needed to exert a stronger force of mastication via increase of the amount of lateral movement rather than that of vertical movement. These findings led us to conclude that while both the vertical and lateral movements increase with increasing hardness level of a test food (within the range of hardness that can be chewed normally), the degree of increase differs between the vertical and lateral movements depending on the hardness level of the food and that changes in the degrees of vertical and lateral movements vary among individuals.

There is no consensus as to cycle time, in that some reports suggest prolongation of the cycle time with increasing hardness of food [5, 6, 11, 15], while others have documented no appreciable change in the cycle time even for foods of higher hardness levels [10, 14, 16]. On closer scrutiny, however, all the results of the previous studies show a tendency for the cycle time to be longer during the chewing of hard food than during that of soft food. Kitashima et al. [24] examined the cycle time for mastication of hard gummy jelly and reported that there was no significant difference in the cycle time among the stages of mastication, but that the cycle time in the initial stage, when the food was still hard, tended to be longer than that in the middle and final stages. Slavicek et al. [25] investigated the movement for mastication of three types gummy jellies created by changing the amount of gelatin and reported that the number of chewing strokes varied only marginally.

The result of this study revealed that the cycle time was prolonged progressively with increasing hardness of the food, with a significant difference between the 6 and the $10 \%$. Based on these findings, it is presumed that the cycle 
time usually increases as the hardness level of the food increases. However, unlike other indices in this study, a significant difference in the cycle time was not found between the 6 and the $8 \%$ or between the 8 and the $10 \%$. The mean ratio of cycle time for gummy jellies with gelatin contents of 6 and $8 \%$ and for those with gelatin contents of 8 and $10 \%$ were approximately 1.0 . This may indicate that the amount of change in the cycle time to maintain this masticatory rhythm is low, because the basic masticatory rhythm is set by the pattern generator in the brain stem.

However, the ratio ranged from 0.90 to 1.07 for gummy jellies with gelatin contents of 6 and $8 \%$ and $0.89-1.07$ for those with gelatin contents of 8 and $10 \%$. This shows that the cycle time was approximately 1.0 , on average, because there were subjects in whom the cycle time increased and those in whom the cycle time decreased, and not because the cycle time remained unchanged irrespective of differences in the hardness level of the food. Thus, it is presumed that there are considerable changes within a particular subject depending on the hardness level of the food. However, based on the finding that the cycle time for chewing gummy jelly with a gelatin content of $10 \%$ was significantly longer than that for chewing gummy jelly with a gelatin content of $6 \%$, it seems that the cycle time varies according to differences in the hardness level of the food and basically increases as the hardness level increases.

It has been reported by various researchers, other than Pröschel et al. [5], that the movement velocity increases with increasing hardness level of the food. In this study also, the movement velocity increased with increase in the hardness level of the food, and there was a significant difference between the movement velocities for gummy jellies with gelatin contents of 6 and $8 \%$, and for those with gelatin contents of 6 and $10 \%$.

These results were consistent with those for changes in the opening distance. However, when the ratio was investigated, the ratio of the 10 to the $8 \%$ was less than 1 in about a half of the subjects ( 9 of 20 subjects). In contrast, the ratio of the maximum opening velocity was less than 1 in only 4 subjects and that of the maximum closing velocity was less than 1 in only 5 of the 20 subjects, showing a pattern slightly different from that for the opening distance. Thus, although there was no significant difference, it became apparent that the velocities increased in the majority of subjects. It was found that the amount of lateral movement, represented by the masticatory width, increased with increase of the gelatin content of the gummy jelly from 8 to $10 \%$. These findings suggest that the muscular activity increases with increasing hardness level of the food via augmentation of the amount of movement and the movement velocity, to exert a stronger force of mastication, although there were individual differences.
There is no report yet, to the best of our knowledge, on the stability of the masticatory movement in relation to hardness level of foods so that no comparison can be made in this respect. In this study, all the parameters reflecting stability of movement showed the lowest values for the food with a gelatin content of $8 \%$, with the values tending to increase in the order of the gelatin content of the food of 6 and $10 \%$. These findings are considered to indicate the existence of an optimal degree of hardness of foods.

\section{Conclusion}

To clarify the changes in the mandibular movements during mastication in relation to varying hardness levels of the test food, we analyzed the opening distance, masticatory width, cycle time, movement velocity, and masseter muscle activity in healthy subjects during mastication of gummy jellies of varying hardness levels. The results suggest that in response to differences in the hardness level of the food, masseter muscular activity sufficient for the hardness of the test food is exerted through alteration of the pathway, rhythm, and velocity of the masticatory movements.

\section{Compliance with ethical standards}

Conflict of interest The authors declare that they have no conflict of interest.

Open Access This article is distributed under the terms of the Creative Commons Attribution 4.0 International License (http://crea tivecommons.org/licenses/by/4.0/), which permits unrestricted use, distribution, and reproduction in any medium, provided you give appropriate credit to the original author(s) and the source, provide a link to the Creative Commons license, and indicate if changes were made.

\section{References}

1. Lund JP. Mastication and its control by the brain stem. Crit Rev Oral Biol Med. 1991;2:33-64.

2. Trulsson M, Johansson RS. Encoding of tooth loads by human periodontal afferents and their role in jaw motor control. Prog Neurobiol. 1996;49:267-84.

3. van der Bilt A, Engelen L, Pereira LJ, van der Glas HW, Abbink JH. Oral physiology and mastication. Physiol Behav. 2006;89:22-7.

4. Trulsson M. Sensory-motor function of human periodontal mechanoreceptors. J Oral Rehabil. 2006;33:262-73.

5. Pröschel P, Hofmann M. Frontal chewing patterns of the incisor point and their dependence on resistance of food and type of occlusion. J Prosthet Dent. 1988;59:617-24.

6. Nakamura $T$, Inoue $T$, Ishigaki $S$, Morimoto $T$, Maruyama $T$. Differences in mandibular movements and muscle activities between natural and guided chewing cycles. Int $\mathrm{J}$ Prosthodont. 1989;2:249-53. 
7. Horio T, Kawamura Y. Effects of texture of food on chewing patterns in the human subject. J Oral Rehabil. 1989;16:177-83.

8. Miyawaki S, Ohkochi N, Kawakami T, Sugimura M. Effect of food size on the movement of the mandibular first molars and condyles during deliberate unilateral mastication in humans. J Dent Res. 2000;79:1525-31.

9. Shiga H, Stohler CS, Kobayashi Y. The effect of bolus size on the chewing cycle in humans. Odontology. 2001;89:49-53.

10. Anderson K, Throckmorton GS, Buschang PH, Hayasaki H. The effects of bolus hardness on masticatory kinematics. J Oral Rehabil. 2002;29:689-96.

11. Peyron MA, Lassauzay C, Woda A. Effects of increased hardness on jaw movement and muscle activity during chewing of viscoelastic model foods. Exp Brain Res. 2002;142:41-51.

12. Bhatka R, Throckmorton GS, Wintergerst AM, Hutchins B, Buschang PH. Bolus size and unilateral chewing cycle kinematics. Arch Oral Biol. 2004;49:559-66.

13. Gavião MB, Engelen L, van der Bilt A. Chewing behavior and salivary secretion. Eur J Oral Sci. 2004;112:19-24.

14. Foster KD, Woda A, Peyron MA. Effect of texture of plastic and elastic model foods on the parameters of mastication. J Neurophysiol. 2006;95:3469-79.

15. Kohyama K, Sawada H, Nonaka M, Kobori C, Hayakawa F, Sasaki T. Textural evaluation of rice cake by chewing and swallowing measurements on human subjects. Biosci Biotechnol Biochem. 2007;71:358-65.

16. Piancino MG, Bracco P, Vallelonga T, Merlo A, Farina D. Effect of bolus hardness on the chewing pattern and activation of masticatory muscles in subjects with normal dental occlusion. J Electromyogr Kinesiol. 2008;18:931-7.

17. Yoshida T, Ishikawa H, Yoshida N, Hisanaga Y. Analysis of masseter muscle oxygenation and mandibular movement during experimental gum chewing with different hardness. Acta Odontol Scand. 2009;67:113-21.

18. Grigoriadis A, Johansson RS, Trulsson M. Temporal profile and amplitude of human masseter muscle activity is adapted to food properties during individual chewing cycles. J Oral Rehabil. 2014;41:367-73.

19. Tanaka A, Shiga H, Kobayashi Y. Quantitative evaluation of mandibular movements and masticatory muscular activities by analyzing the amount of glucose discharge during gumi-jelly chewing. J Jpn Prosthodont Soc. 1994;38:1281-94.

20. Shiga H, Kobayashi Y, Arakawa I, Yokoyama M, Unno M. Validation of a portable blood glucose testing device in measuring masticatory performance. Prosthodont Res Pract. 2006;5:15-20.

21. Inaba J, Shiga H, Kobayashi Y. Peripheral feedback adjustment in chewing various types of food. J Jpn Prosthodont Soc. 2001;45:271-82.

22. Shiga H, Kobayashi Y, Stohler CS, Tanaka A. Section showing minimal intra-individual variations in masticatory movement. J Jpn Prosthodont Soc. 2008;52:200-4.

23. Tamura K, Shiga H. Gender differences in masticatory movement path and rhythm in dentate adults. J Prosthodont Res. 2014;58:237-42.

24. Kitashima F, Tomonari H, Kuninori T, Uehara S, Miyawaki S. Modulation of the masticatory path at the mandibular first molar throughout the masticatory sequence of a hard gummy jelly in normal occlusion. Cranio. 2015;33:263-70.

25. Slavicek G, Soykher M, Gruber H, Siegl P, Oxtoby M. A novel standard food model to analyze the individual parameters of human mastication. J Stomatol Occ Med. 2009;2:163-74. 